\title{
Wave pattern simulation around the breakwater configuration in Bantan coast, Bengkalis
}

\author{
Bambang Sujatmoko ${ }^{1, *}$, Manyuk Fauzi ${ }^{1}$, and Doli Ananta Putra ${ }^{1}$ \\ ${ }^{1}$ Department of Civil Engineering, Universitas Riau, Pekanbaru, Indonesia
}

\begin{abstract}
Bantan Coast in Bengkalis Island that suffered worst abrasion due to wave attack. Protection of abrasion area against the wave can be done by proper lay-out of breakwater with certain configuration. To get the optimal configuration of breakwater, wave pattern around the breakwater were analyzed quantitatively. It was conducted to obtain the optimum condition of wave height reduction produced. Evaluation of breakwater lay-out effect to wave pattern can be done by numerical model approached. Wave pattern simulation that occurred due to the breakwater was done by Surface water Modelling System (SMS) - CGWAVE software module. This module is a 2-D depth average numerical model using finite element model. To get accurate simulation, a deviation of the numerical result and the measurement result at several locations was used as the indicator parameter in the calibration process. The results showed that from the result of calibration process was used 1.3 meters wave height and 5.4 seconds wave period. Three breakwaters 20 meters slit configuration produced a maximum value of wave height reduction and wave velocity reduction (in comparison wave simulation without breakwater). This configuration produces $60 \%$ height reduction and $14 \%$ velocity reduction.
\end{abstract}

\section{Introduction}

According to research [1], the most of the northern coast Bengkalis's Island has abrasion occurred. The north coast of western Bengkalis is the most severe abrasion beach. In the last 26 years, there has been abrasion in Bengkalis Island with an average abrasion rate of $59 \mathrm{ha} /$ year. This is one of the reasons why this coastal abrasion problem needs to be studied. Studies on this abrasion problem can be done one of them with theoretical and mathematical studies. Construction of the breakwater can be done by first knowing the wave conditions that occur in the coast. This condition can be estimated by applying the numerical model approach.

The purpose of this research is to analyze the wave height which is reduced due to the variation of the use of the building configuration of breakwaters to surface wave changes that occur by using SMS application.

The case of the study in this research are:

1. This research uses daily wind data of Pinang Kampai station, Dumai, obtained from BMKG data of 2016,

*Corresponding author: b_sujatmoko@yahoo.com 
2. The bathymetry map obtained from the field survey of PT. Indhie Jaya Teknik,

3. Ship Flow Section Map obtained from the Hydro-Oceanography Office 2014,

4. Simulation wave pattern and model calibration using SMS program (Surface Water Modeling System) on CGWAVE module,

\subsection{Wave forecasting}

The wave forecasting $[2,3,4]$ requires data for generating the wave such as wind speed $(\mathrm{U})$, wind blow duration ( $\mathrm{t}$ ), the dominant direction of the wind rose, and fetch $(\mathrm{F})$. The wind data [2] used for wave forecasting is the sea-level wind data at the generating site on the review object. The data used to be converted [2,3] so that it can be used as the calculation data for in-depth sea wave forecasting. Generally, data measurement of wind data that is easy to get is windspeed measurement conducted on land. However, the waves are generated by winds that are above the sea and need transformation using Fig. 1.

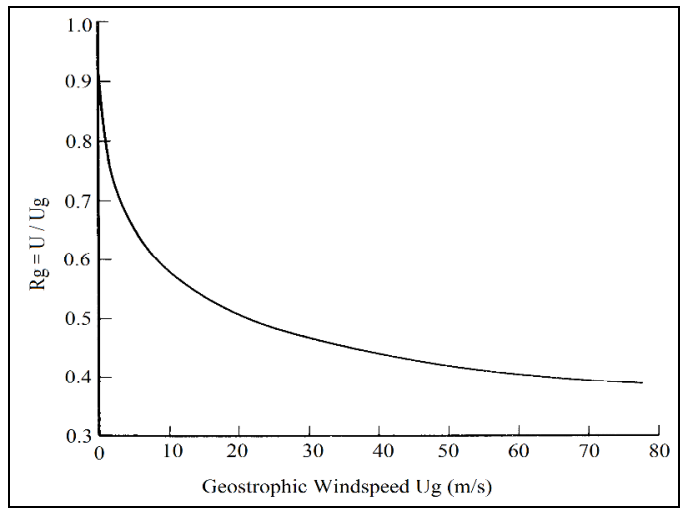

Fig. 1. Ratio of Rg windspeed U at 10-meter elevation to geostrophic windspeed Ug. [3].

The wind speed $[2,3]$ over the ocean will be converted then into a wind-stress factor (UA). The wind-stress factor becomes one of the variables on wave forecasting. This windstress factor is shown by Eq. 1 .

$$
\mathrm{U}_{\mathrm{A}}=0,71 \times \mathrm{U}^{1,23}
$$

Fetch $[2,5]$ is a sea wave generator area bounded by the land surrounding the sea. The waves that occur are not only generated in the same direction but also by the angle and direction of the dominant wind. The dominant region of the wind is called the fetch region. The fetch length is calculated to get an effective fetch length by using Eq. 2 .

$$
F_{\text {eff }}=\frac{\sum_{i=1}^{N}\left(F i \times \cos \alpha_{i}\right)}{\sum_{i=1}^{N}\left(\cos \alpha_{i}\right)}
$$

\subsection{Wave prediction}

The wave generator is a method $[2,3,4]$ for knowing significant ocean waves inside. Based on [3] the equation of wave forecasting empirical method can use Eq. 3 to obtain wind duration, ( $\mathrm{t}$ ) in hours. 


$$
\frac{g t}{U_{A}}=6.88 \times 10^{1}\left(\frac{g F}{U_{A}^{2}}\right)^{\frac{2}{3}}
$$

Plan wave height, H0 (m) can be calculated by using Eq. 6

$$
\frac{g H_{m_{o}}}{U_{A}^{2}}=1.6 \times 10^{-3}\left(\frac{g F}{U_{A}^{2}}\right)^{\frac{1}{2}}
$$

The plan wave period, T (seconds) can be calculated by using Eq. 5

$$
\frac{g T_{m}}{U_{A}}=2.857 \times 10^{-1}\left(\frac{g F}{U_{A}^{2}}\right)^{\frac{1}{3}}
$$

Forecasting $[2,4]$ the wave nomogram method can use graphics in Fig. 2. When the fetch length (F), wind voltage factor (UA) and duration are known then the duration, height and significant wave period can be calculated from the intersection of values (F) and (UA).

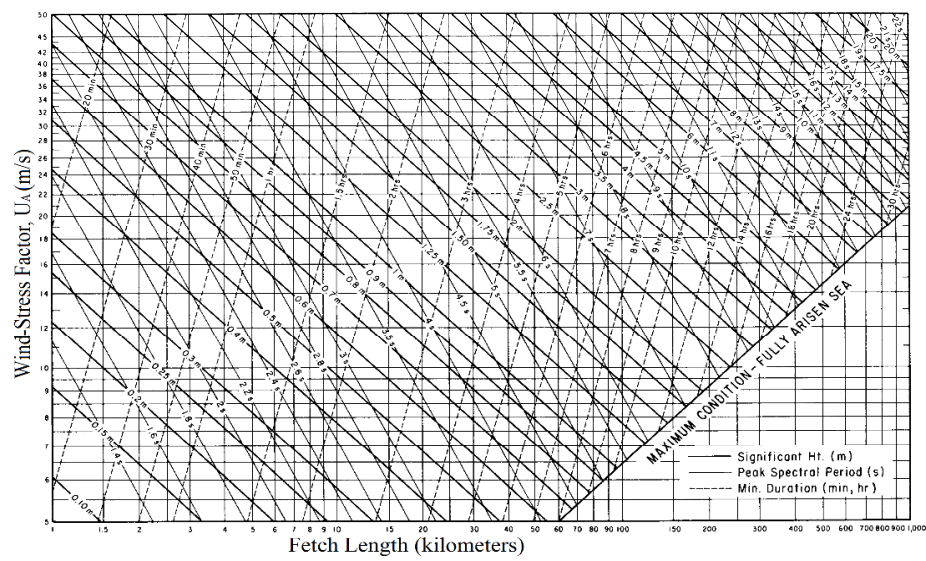

Fig. 2. Wave prediction nomogram graphic [3].

\subsection{Breakwater}

The breakwaters [2] can be divided into two types: detached and offshore breakwater. Detached breakwater type used for harbor protection. Type of offshore breakwater used for coastal protection. In extended coastal conditions that are long enough and serves to protect against abrasion then, it can be built the offshore wave breaker series.

\subsection{CG-WAVE}

Research [5] uses a field approach to simulate/modeling the wave condition with program Surface-water Modeling System (SMS) version 10.0 CGWAVE module. CGWAVE [6] (Coastal surface water Wave) can be used to predict linear wave propagation across regions with irregular bathymetry conditions. Governing equation of the settlement (Eq. 6) in the 
diffraction-diffraction model is a modified wave propagation equation of mild slope equation for monochromatic linear waves [7].

$$
\nabla .\left(\mathrm{C} C_{g} \nabla \dot{\eta}\right)+\frac{C_{g}}{C} \sigma^{2} \dot{\eta}=0
$$

where $\eta^{\prime}(x, y)$ is estimated wave surface elevation function, $\sigma$ is wave frequence ( $\left.\mathrm{rad} / \mathrm{s}\right)$, $\mathrm{C}(\mathrm{x}, \mathrm{y})$ is wave velocity $(\sigma / \mathrm{k}), \mathrm{C}_{\mathrm{g}}$ is velocity of wave group $(\delta \sigma / \delta \mathrm{k}=\mathrm{nC})$, and $\mathrm{k}(\mathrm{x}, \mathrm{y})$ is wave number $(=2 \pi / \mathrm{L})$, in related to the depth $\mathrm{d}(\mathrm{x}, \mathrm{y})$ through linier dispersion $\left(\sigma^{2}=\mathrm{g} k \tanh (\mathrm{kd})\right)$.

\section{Methodology}

\subsection{Object location}

The location [8] of the research object, geographically can be seen in Fig. 3. The geographical coordinates of the research review object are $1^{\circ} 32^{\prime} 54.64 "$ LU and $102^{\circ} 19^{\prime} 35.97 "$ BT. The research data consist of Batimetri Beach Bantan map, Bengkalis Island cruise shipping map, 2012-2016 wind data and fetch map.

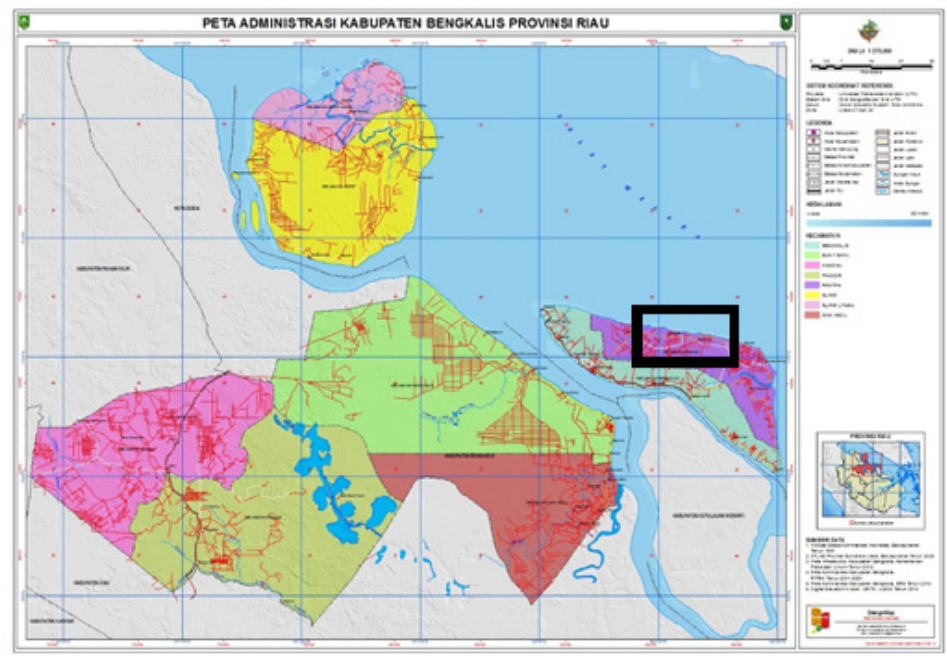

Fig. 3. Bengkalis district's administration map [8].

\subsection{Research procedure}

The research procedure consists of a data processing stage (wind and bathymetry map), sea wave forecasting, wave pattern modeling, model calibration, presentation of results and discussion and conclusions. Flowchart of this research procedure can be seen in Fig. 4.

\subsection{Configuration breakwater}

The position of breakwater configuration that be varied and simulation as same as the position of the breakwater existing. The scheme and the result of the breakwater simulation in this research are done in some conditions of breakwater configuration which will be used 
can be seen in Table 1 and Fig. 5 for breakwater's simulation result and the particle movement.
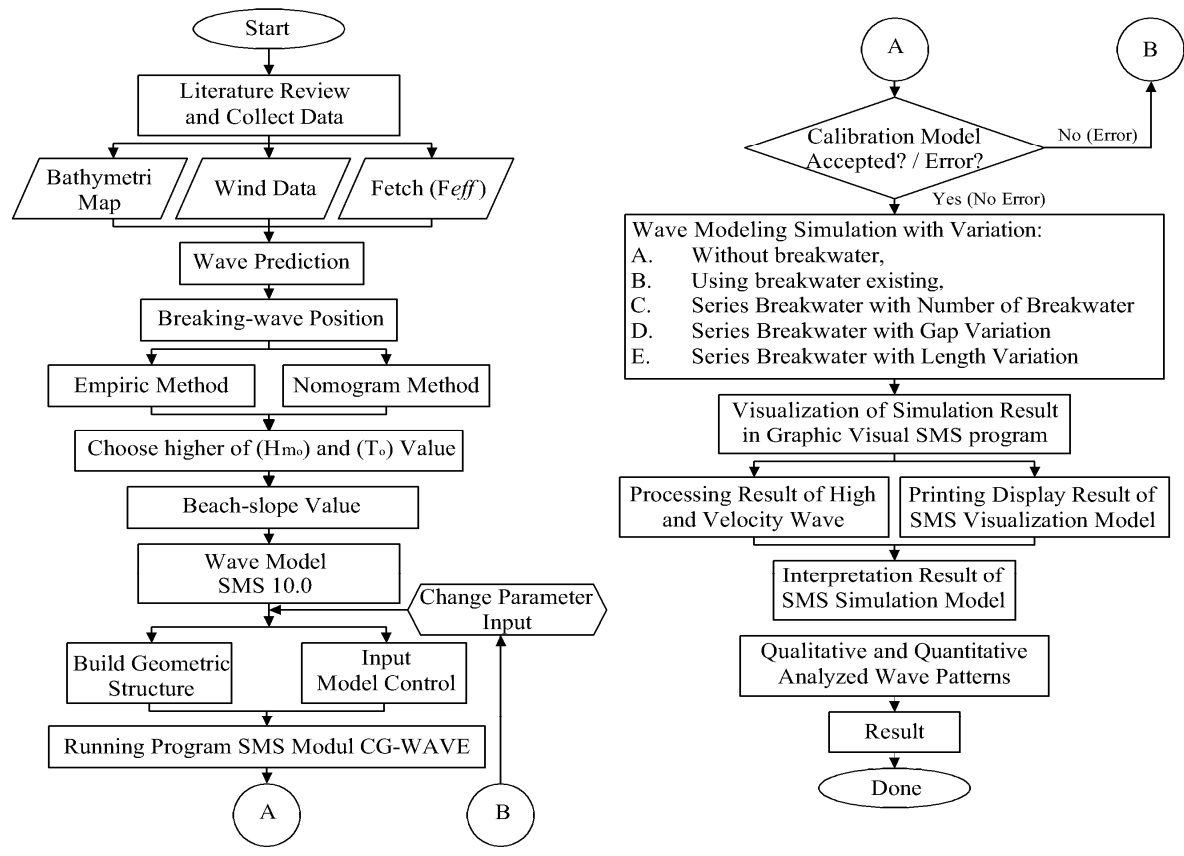

Fig. 4. Flowchart of research procedure.

Table 1. Breakwater's configuration scheme simulation.

\begin{tabular}{|c|c|c|}
\hline Conditions & Configuration & Specifications \\
\hline A & None Breakwater & - \\
\hline B & Existing Breakwater Series & Length $=207 \mathrm{~m} ;$ Slit $=20 \mathrm{~m}$ \\
\hline $\mathrm{C} 1$ & 1 Breakwater & $\mathrm{L}=90 \mathrm{~m} ;$ Slit $=0 \mathrm{~m}$ \\
\hline $\mathrm{C} 2, \mathrm{C} 3$ & 2, and 3 Breakwater & $\mathrm{L}=90 \mathrm{~m} ;$ Slit $=20 \mathrm{~m}-\mathrm{L}=90 \mathrm{~m} ; \mathrm{Slit}=20 \mathrm{~m}$ \\
\hline $\begin{array}{c}\text { D1, } \\
\text { D2, D3 }\end{array}$ & 2 Breakwaters Series & $\begin{array}{c}\mathrm{L}=200 \mathrm{~m} ; \text { Slit }=10 \mathrm{~m} \\
\mathrm{~L}=200 \mathrm{~m} ; \text { Slit }=15 \mathrm{~m} ; \mathrm{L}=200 \mathrm{~m} ; \text { Slit }=20 \mathrm{~m}\end{array}$ \\
\hline $\mathrm{E} 1, \mathrm{E} 2, \mathrm{E} 3$ & Single Breakwater & $\mathrm{L} 1=90 \mathrm{~m} ; \mathrm{L} 2=200 \mathrm{~m} ; \mathrm{L} 3=250 \mathrm{~m}$ \\
\hline
\end{tabular}
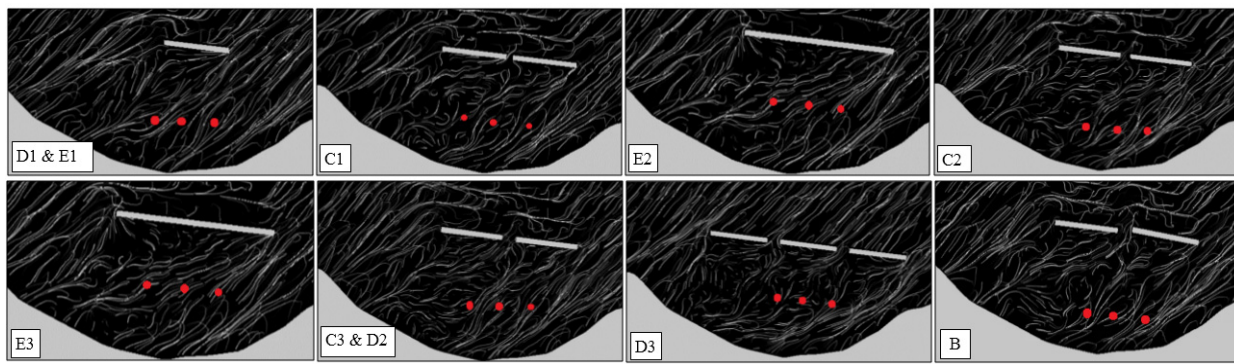

Fig. 5. Breakwater's simulation result in some configuration scheme and the particle movement. 


\subsection{Model calibration}

The process of adjustment is done by calibration qualitatively and quantitatively. The qualitative calibration is done by looking at the wave peak pattern generated from the modeling with the wave state on the coast. Quantitative calibration is done by looking at the magnitude of the wave height generated from the modeling with the magnitude of the wave height that occurs on the coast. Model calibration using SMS (Surface Water Modeling System) 10.0-CGWAVE module is done by trial and error's method to get wave pattern value according to field condition.

\section{Results and discussion}

The characteristic wave result from wave forecasting is 1.3 meters wave height and 5.4 second period on water depth. This result has to be calibrated by approached field condition. The specified point of view on object location giving by point 1,2 , and 3 . This point is located as same as breakwater existing position. Point 1 to 3 will be a fixed point that will show the wave height on other condition variations. Main condition simulation results can be seen in Fig. 6 .

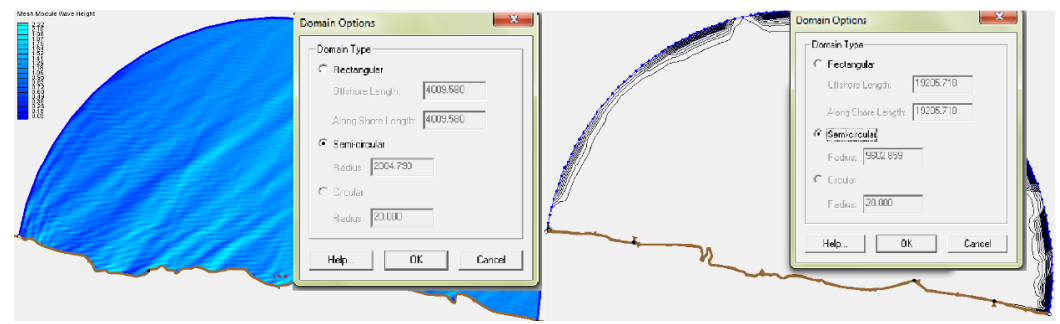

Fig. 6. Calibration model by radius catchment modeling adjusted.

\subsection{Calibration model}

Calibration of the model using SMS (Surface Water Modeling System) 10.0-CGWAVE module is done by trial and error's method to get wave pattern value according to field condition. The calibration step is shown as step (a) until (d) on Fig. 6 and Fig. 7.

The quantitative calibration modeling scheme is the same as the qualitative calibration modeling scheme. Quantitative calibration results can be seen in Table 3 and the resulting wave contour use Fig. 6 (d).

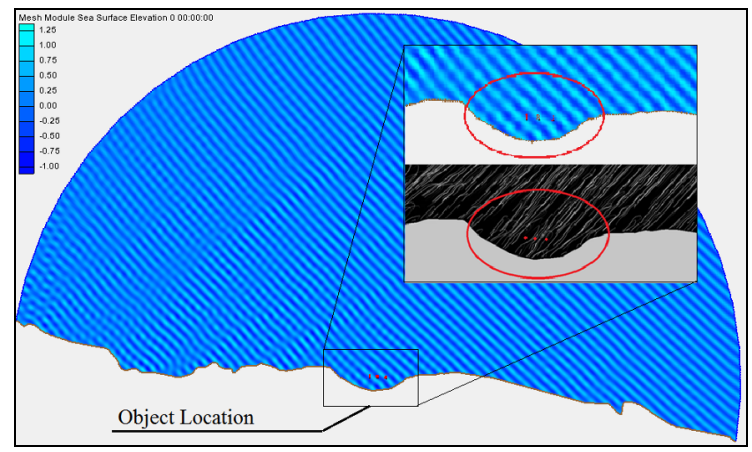

Fig. 7. Wave high contour and wave pattern by SMS modeling. 
Wave height achieved at object point is $1.3 \mathrm{~m}$ using smaller radius model (2000 meters) and used 5.4 second period, and 0.67 meters amplitude or 1.3 meters wave height as wave parameter model control input. Shown at Table 2.

Table 2. Quantitative calibration scheme to model control input.

\begin{tabular}{|c|c|}
\hline Radius size model & Quantitative calibration \\
\hline Bigger Radius & $\mathrm{T}=5.4 \mathrm{~s} ; \mathrm{A}=0.67 \mathrm{~m} ; \mathrm{H}=0.001 \mathrm{~m}$ \\
\hline Smaller Radius & $\mathrm{T}=5.4 \mathrm{~s} ; \mathrm{A}=0.67 \mathrm{~m} ; \mathrm{H}=1.3 \mathrm{~m}$ \\
\hline
\end{tabular}

Table 3. Percentage of wave height reduction in variation of breakwater configuration.

\begin{tabular}{|c|c|c|c|c|c|}
\hline \multirow{2}{*}{$\begin{array}{c}\text { Breakwater } \\
\text { Configuration }\end{array}$} & Point 1 & Point 2 & Point 3 & \multirow{2}{*}{ Average (m) } & \multirow{2}{*}{ Reduce (\%) } \\
\hline & \multicolumn{3}{|c|}{$V(\mathbf{m})$} & & \\
\hline (2) & (3) & (4) & (6) & (7) & (7) \\
\hline $\begin{array}{l}\text { Main condition } \\
\text { (no breakwater) }\end{array}$ & 1.150 & 1.440 & 1.190 & 1.260 & - \\
\hline 3 Breakwater $(\mathrm{slit}=20 \mathrm{~m})$ & 0.240 & 0.350 & 0.910 & 0.500 & $60.32 \%$ \\
\hline 2 Breakwater $(\mathrm{slit}=20 \mathrm{~m})$ & 0.350 & 0.460 & 1.120 & 0.643 & $48.94 \%$ \\
\hline 1 Breakwater & 0.610 & 0.670 & 0.810 & 0.697 & $44.71 \%$ \\
\hline
\end{tabular}

\subsection{Wave height reduction}

The wave height reduction with the optimal percentage was found by number breakwater variation with three breakwaters 20 meters slit configuration is $60.32 \%$. The valued that shown optimal condition of breakwater configuration can be seen on wave height reduction at Table 3 and Fig. 9 for graphic the effect of the breakwater.

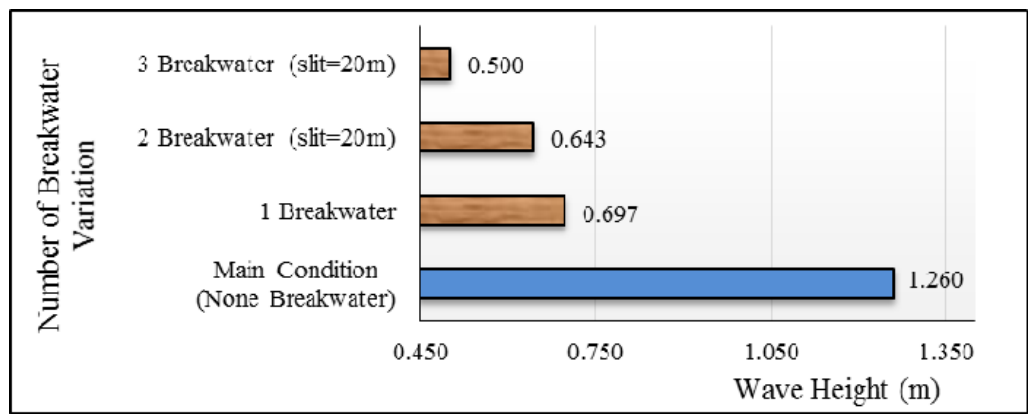

Fig. 8. Graphic the effect of amount of breakwater on the wave height reduction.

\subsection{Wave velocity reduction}

The change in wave velocity that occurs behind the breakwater due to variations of the breakwaters configuration. The value record by Vx and Vy from the wave velocity on SMS 
software, then the resultant value was calculated. The wave velocity reduction with the optimal percentage was found by number breakwater variation with three breakwater 20 meters slit configuration is $14.05 \%$. The valued that shown optimal condition of breakwater configuration can be seen on wave velocity reduction at Table 4 and Fig. 10 for graphic the effect of the breakwater.

Table 4. Percentage of wave velocity reduction in variation of breakwater configuration.

\begin{tabular}{|c|c|c|c|c|c|}
\hline \multirow{2}{*}{$\begin{array}{c}\text { Breakwater } \\
\text { Configuration }\end{array}$} & Point 1 & Point 2 & Point 3 & \multirow{2}{*}{ Average (m) } & \multirow{2}{*}{ Reduce (\%) } \\
\hline & \multicolumn{3}{|c|}{$\mathbf{V}(\mathbf{m})$} & & \\
\hline (2) & (3) & (4) & (6) & (7) & (7) \\
\hline $\begin{array}{l}\text { Main condition } \\
\text { (no breakwater) }\end{array}$ & 0.138 & 0.140 & 0.146 & 0.141 & - \\
\hline 3 Breakwater $(\mathrm{slit}=20 \mathrm{~m})$ & 0.127 & 0.099 & 0.137 & 0.121 & $14.05 \%$ \\
\hline 2 Breakwater $(\mathrm{slit}=20 \mathrm{~m})$ & 0.144 & 0.140 & 0.135 & 0.140 & $1.03 \%$ \\
\hline 1 Breakwater & 0.146 & 0.152 & 0.148 & 0.149 & - \\
\hline
\end{tabular}

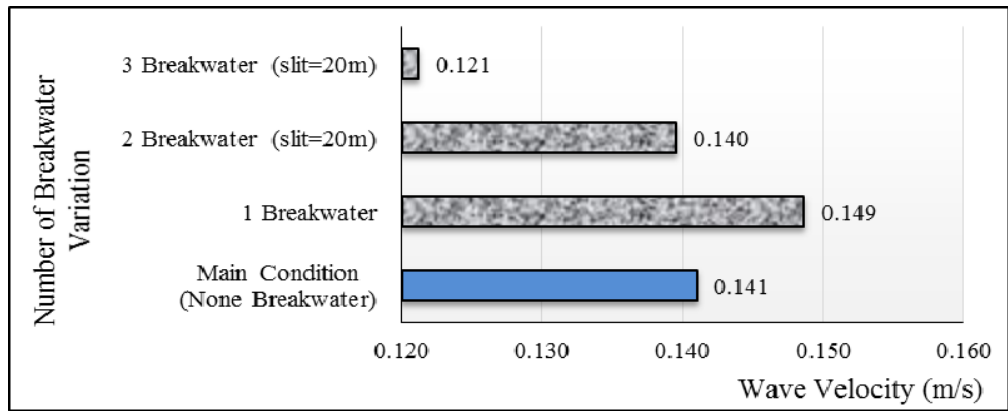

Fig. 9. Graphic the effect of amount of breakwater on the wave velocity reduction.

\section{Conclusions}

The wave characteristics calculated from wave forecasting prediction are 5.4 periods and 1.3 meters wave height. Model calibrated with 2000 meters smaller radius parameter changed. The breakwater configuration that has the optimal wave height reduction value if its comparison wave simulation without breakwater. Three breakwaters 20 meters slit configuration produced a maximum value of wave height reduction and wave velocity reduction (in comparison wave simulation without breakwater). This configuration produces a $60 \%$ height reduction and $14 \%$ velocity reduction.

\section{References}

1. S. Sutikno, D.P. Handoyo, M. Fauzi, K. Murakami. Proceedings ACES (Annual Civil Engineering Seminar) (2015)

2. B. Triadmodjo, Teknik Pantai (Gadjah Mada Press, Yogyakarta, 1999) 
3. USA A.C. Engineer, Shore Protection Manual I (1984)

4. F. Rabung, Prosiding 2014 Hasil Penelitian Teknologi Terapan Group Teknik Sipil, 8 (2014)

5. Zulkifli, H.M. Thaha, R. Karamma, Simulasi gelombang perairan Sulaa kota Baubau dengan menggunakan SMS (Surface Water Modeling System) (Undergraduate Thesis, Universitas Hasanuddin, Makasar, 2016)

6. Aquaveo ${ }^{C}$, Surface water modeling system (2011)

7. J.C.W. Berkhoff, N. Booij, R.C. Radder, Coastal Engineering, 6 (1982)

8. Peta Tematik Indonesia, Administrasi kabupaten Bengkalis. Available at: https://petatematikindo.wordpress.com/2014/09/01/administasi-kabupaten-bengkalis/ (2014) 